\title{
EVALUATION OF EXTRACTS FROM DRY FRUITS BLACK BLUEBERRY (VACCINIUM MYRTILLUS L.) THROUGH ONE- DIMENSIONAL AND MULTIDIMENSIONAL REGRESSION ANALYSIS FOR PHENOLCARBOXYLIC ACIDS
}

\author{
Radostina Stefanova, Antoaneta Georgieva, Krasimir Krastev \\ Facultyof Technics and Technologies, Trakia University \\ Graf Ignatiev 38, 8600 Yambol, Bulgaria, e-mail: r_yorgovi@yahoo.com
}

\begin{abstract}
The purpose of the study is to develop a technology for the production of dried blackberry extracts. Basic extraction parameters are established. The influence of the technological parameters of the extraction process on the content of phenolcarboxylic acids in blackberry extracts is analyzed. The extracts obtained were determined with the amount of phenolcarboxylic acids for use in enriching fruit juices with biologically active substances. The effect of the type of extractant, the duration and temperature of the extraction and the hydromodule on the color parameters were investigated. The results of the planned experiment were statistically processed with the Statistica program. The residuals were estimated and analyzed by normal probability of the residual schedule, the scatterplot of the residuals from the predicted values, and the frequency histogram of the residuals. All results are presented analytically and graphically.
\end{abstract}

Keywords: extracts, dried fruit blackberry, phenolecarboxylic acids, regression analysis.

\section{INTRODUCTION}

Studies conducted in different countries confirm that one of the main causes of pathological changes in the human body leading to premature aging and development of cardiovascular diseases, cancer and diabetes is the excessive accumulation of free radicals and reactive oxygen species in the biological fluid of the biological fluid. .

Regular use of fruits and berries in which there are many natural phenolic compounds significantly reduce the risk of these diseases. The largest amount of antioxidants is found in blackcurrant, blackberry, grape, garden strawberry and more. Therefore, it is necessary to include natural plant antioxidants in foods, which protect them from oxidation.

Most of the natural antioxidants enter the human body with food. With the systematic use of foods containing natural antioxidants, the incidence of cardiovascular and oncological diseases is significantly reduced.

The healing potential of wild shrub plants lies in their antioxidant, anti-allergic, antiinflammatory and antiviral properties, which depend on polyphenolic complexes.

Blackberry extracts serve as natural antioxidants.

As an alternative to the synthetic antioxidants, natural polyphenols from various plant species may be used. These compounds have an ideal chemical structure to "scavenge" free radicals, demonstrating, at the same time, higher antioxidant capacity (e.g., cyanidin and malvidin) than vitamins $\mathrm{C}$ and $\mathrm{E}$ [1].

Owing to these properties, polyphenols protect and support many functions of organs and systems and in particular the digestive [2], nervous and circulatory systems [3].

Anthocyanins are representative plant pigments widely distributed in colored fruits and flowers. They also exhibit antioxidant activities and therefore may contribute to the prevention of heart disease, cancer, and inflammatory disease $[4,5,6,7,8,9]$. Berries have 


\section{ARTTIE $Y$}

Ipplied Resseirlohes in Technics, Technologies and Eductition

Journal of the Faculty of Technics and Technologies, Trakia University https://sites.google.com/a/trakia-uni.bg/artte/

been known to contain anthocyanin pigments abundantly and thus have been used globally as a medicine or a source of health food/dietary supplement.

In order to increase the nutritional value and antioxidant properties of the juice-containing beverages, extracts of wild raw materials having prophylactic and functional action can be introduced into production technologies.

The purpose of the study is to develop a technology for the production of dried blackberry extracts. Basic extraction parameters are established. The extracts obtained were analyzed for the purpose of enriching fruit juices with phenolic compounds.

\section{MATERIALS AND METHODS}

Object of study are the fruits of Vaccinium myrtillus L. In wild plants are contain a number of chemicals that can affect the vital processes occurring in the human body.

Phenolcarbonic acids-Spectrophotometric by Pharmacopoeia Method [Pharmacopoeia Russia] is the general method of analysis [10].

Mathematical data processing was performed by one-dimensional and multi-dimensional regression analysis. By which were studied and evaluated the possible functional dependencies between two or more random variables. The main questions are whether there is a functional dependence between two dependent random variables and if so - to find a function that describes it sufficiently accurately. Various models have been studied, with the best-described dependencies being selected. Estimates were made on the degree of influence of the factors as well as on their level of significance. Fischer's criterion is assessed, as well as its probability. Residue assessment and analysis was performed by normal probability plot of residues, the scatter plot of the predicted residual values and the residual histogram. All results are presented analytically and graphically.

The processing was done through the statistical program STATISTICA (StatSoft, Inc.).

All data are processed at level of significance $\alpha=0,05$.

\section{RESULTS AND DISCUSSION}

The experimental results obtained from the physicochemical studies of the dried blackberry extracts were used to obtain a regression model as well as to study its suitability. Multiple regression was found between phenolecarboxylic acids, \% as a function of response, ethyl alcohol concentration in percent, and time in minutes. The best model turns out to be:

$$
z=b_{1} x+b_{2} t+b_{3} t^{2}
$$

where $x$ is the concentration of ethyl alcohol in percent, $y$ is the time in minutes and $z$ is the concentration of phenolecarboxylic acid in percent.

After the statistical processing of the data, it can be seen that the coefficient of determination $R^{2}=0,72$, which means that $72 \%$ of the change in the parameter $z$ is due to the control factors $x$ and $y$ is described with the model used. Of all the models studied, the coefficient of certainty is the highest. The statistically significant coefficients of the model are as follows:

$$
b_{1}=0,0083 b_{2}=0,001259 b_{1}=-0,000001
$$

Fisher's criterion, $F(4,40)=10,183, p<0.00194$, and its corresponding probability indicate that the model describes a significant part of the change in $z$. The model performs better than the so-called naive forecasts average values.

IRTIIE Vol. 7, No. 3, 2019 ISSN 1314-8788 (print), ISSN 1314-8796 (online), doi: 10.15547/artte.2019.03.006 


\section{IRTIL $<>$}

Ipplied Resseirlohes in Technics, Technologies and Eductition

Journal of the Faculty of Technics and Technologies, Trakia University https://sites.google.com/a/trakia-uni.bg/artte/

The regression equation is:

$$
z=0,0083 x+0,001259 t-0,000001 t^{2}
$$

The resulting regression model describes the surface $z=f(x, y)$ that we can depict in $R^{3}$

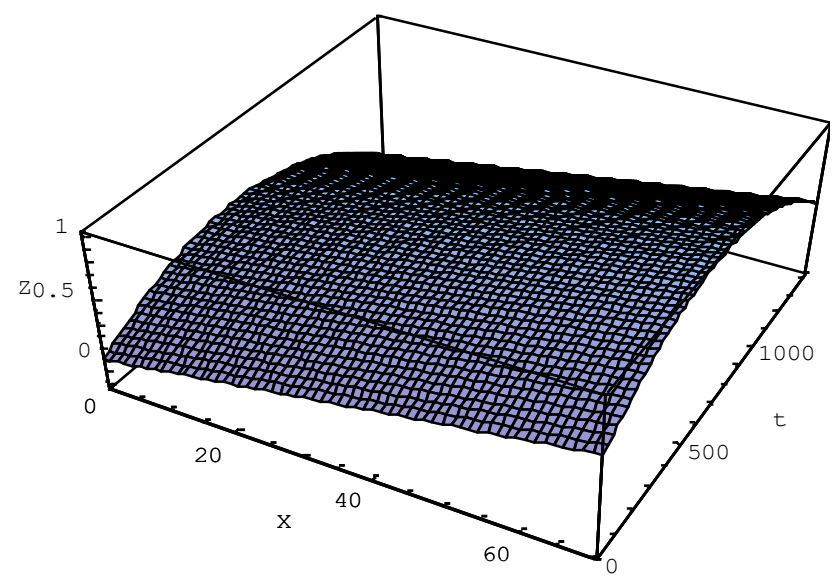

Figure 1. Model response line

The model response line is presented in Figure 1. The analysis of the residuals and their graphical representations are shown in Figure 2 in the so-called normal probability graph.

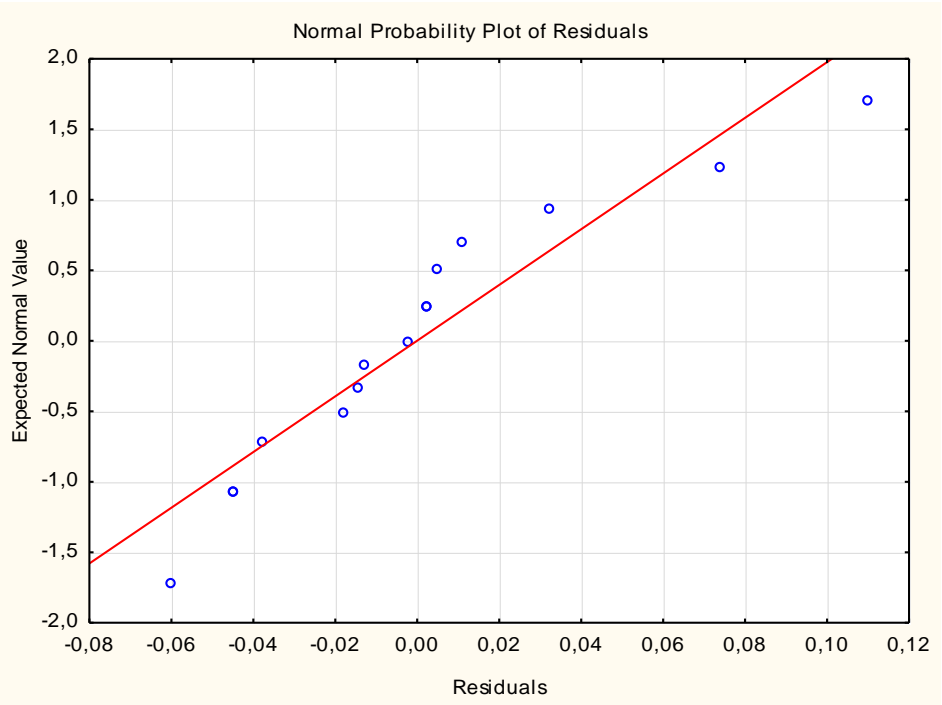

Figure 2. Normal probability plot of residuals

We will check for residual dependence on predicted values from the model. For this purpose, we will analyze the scatterplot of the residuals from the predicted values - Figure 3. 


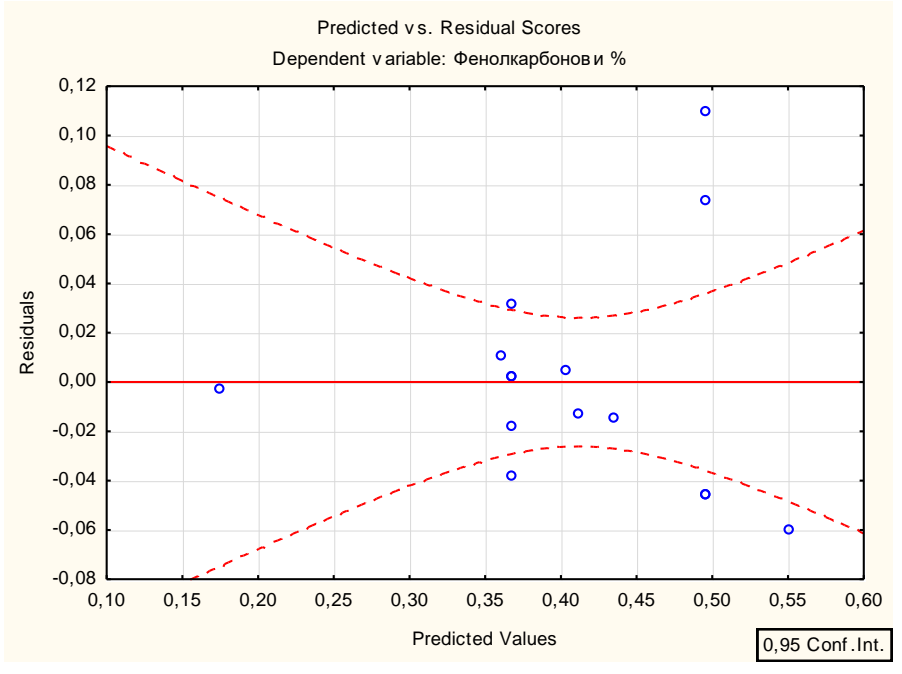

Figure 3. Scatterplot of residual values from predicted values

The obtained graph shows that the systematic residuals are lacking and are sufficiently chaotic in their distribution. We can conclude that the residuals do not depend on the predicted values.

From the obtained results we can draw the following conclusions:

- The resulting model is quadratic and describes the experimental data obtained with great precision.

- From the residual analysis, we can conclude that our model is adequate.

- Concentration and time factors have a relatively similar effect.

The experimental results obtained were also used to obtain a regression model and to find multiple regression between phenolecarboxylic acids, \% as a function of response, ethyl alcohol concentration in percent and temperature. The best model turns out to be:

$$
z=b_{1} x+b_{2} T+b_{3} x^{2}+b_{4} T^{2}
$$

where $x$ is the concentration of ethyl alcohol in percent, $y$ is temperature, and $z$ is phenolecarboxylic acid in percent.

After the statistical processing of the data it is seen that the coefficient of determination $R^{2}=0,85$ which means that $85 \%$ of the change in the parameter $z$ is due to the control factors $x$ and $y$ and is described with the model used. Of all the models studied, the coefficient of certainty is the highest. The statistically significant coefficients of the model are as follows:

$$
b_{1}=0,008338, b_{2}=0,001281, b_{3}=-0,000072 b_{4}=-0,000001
$$

Fisher's criterion, $\mathrm{F}(4,40)=42,661, \mathrm{p}<0.00000$, and its corresponding probability indicate that the model describes a significant part of the change in $z$. The model performs better than the so-called naive average forecasts.

The regression equation is:

$$
y=0,008338 x+0,001281 T-0,000072 x^{2}-0,000001 T^{2}
$$




\section{IRTTE \\ Ipplied Ressearches in Technics, Technologies and Educration \\ Journal of the Faculty of Technics and Technologies, Trakia University https:///ites.google.com/a/trakia-uni.bg/artte/}

The resulting regression model describes the surface $z=f(x, T)$ that we can depict in $R^{3}$.

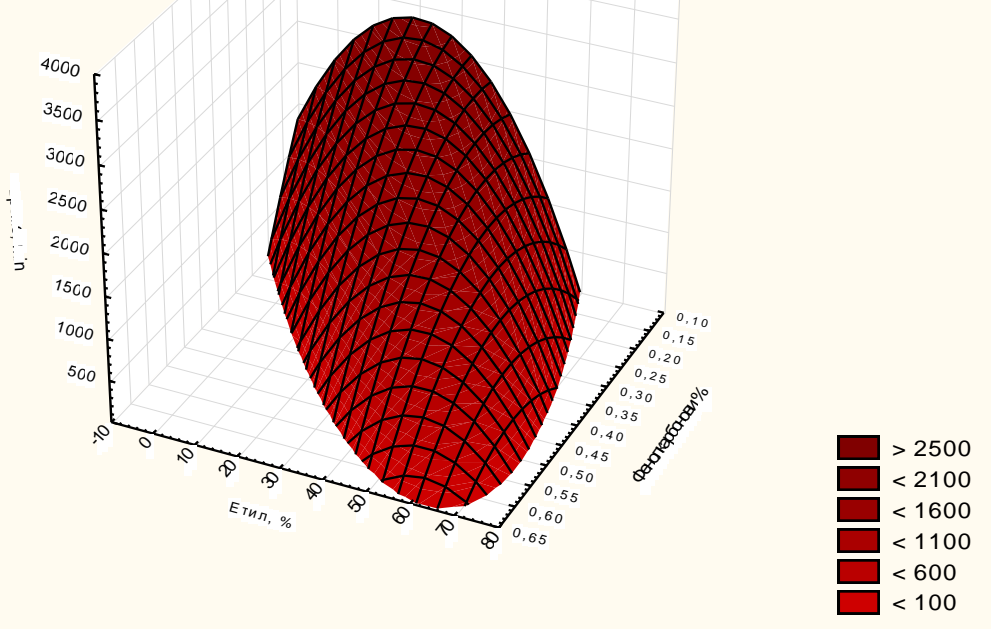

Figure 4. Model response line

The model response line is presented in Figure 4. The analysis of residues and their graphical representations are shown in Figure 5 in the so-called normal probability graph.

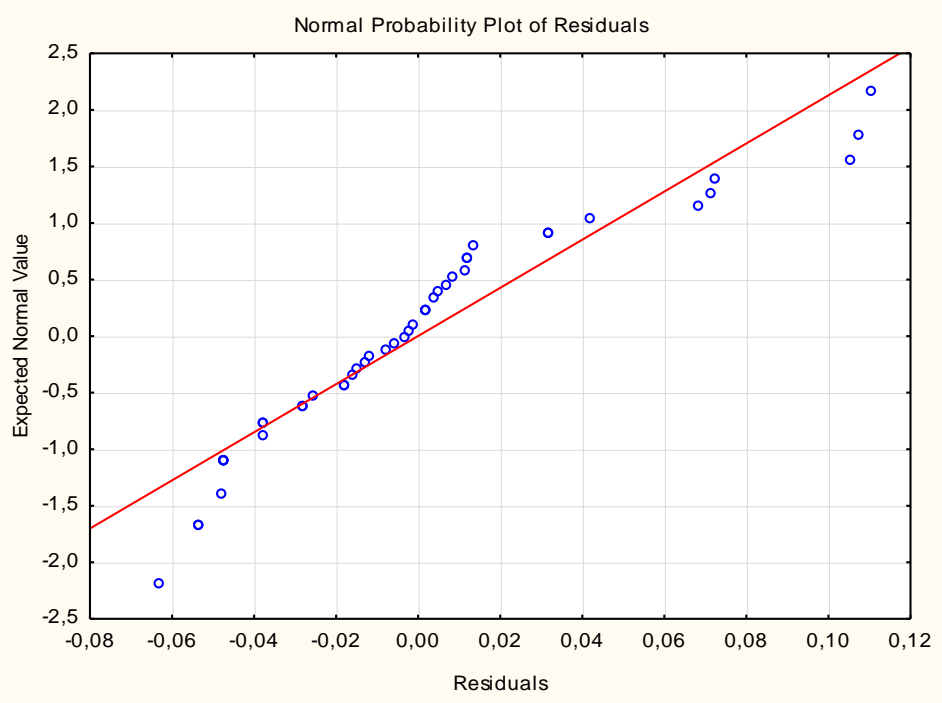

Figure 5. Normal probability plot of residuals

We will check for residual dependence on predicted values from the model. For this purpose, we will analyze the scatterplot of the residuals from the predicted values - Figure 6.

IRTITE Vol. 7, No. 3, 2019 ISSN 1314-8788 (print), ISSN 1314-8796 (online), doi: 10.15547/artte.2019.03.006 


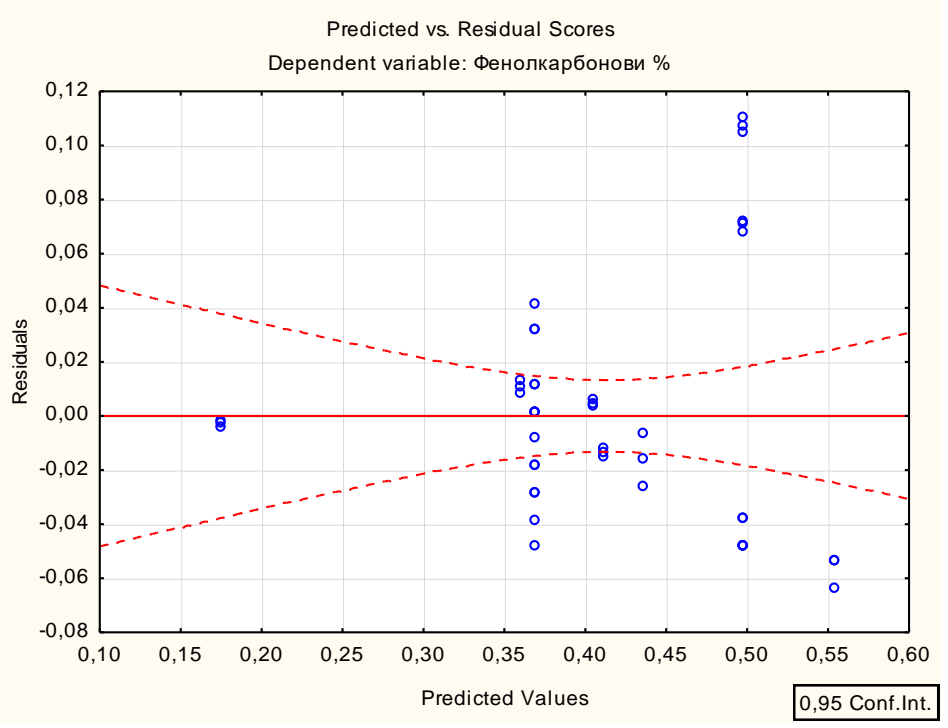

Figure 6. Scatterplot of residual values from predicted values

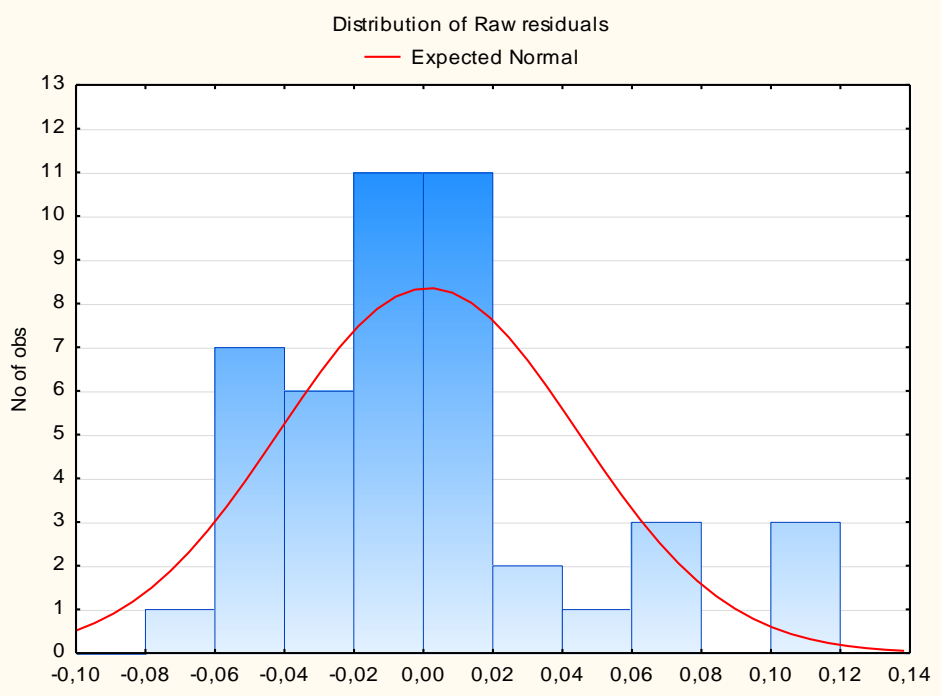

Figure 7. Residual histogram

The obtained graph shows that the systematic residuals are lacking and are sufficiently chaotic in their distribution - Figure 7. We can conclude that the residuals do not depend on the predicted values.

From the obtained results we can draw the following conclusions:

- The resulting model is quadratic and describes the experimental data obtained with great precision.

- From the residual analysis, we can conclude that our model is adequate.

- From the analysis of the standardized bet coefficients, it can be concluded that the time parameter has a 4.5 -fold greater influence on the concentration response. 


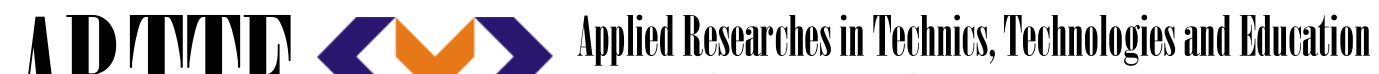 Journal of the Faculty of Technics and Technologies, Trakia University https://sites.google.com/a/trakia-uni.bg/artte/}

A regression model was obtained based on the results obtained, and multiple regression was found between phenolcarboxylic acids, \% as a function of response and concentration of ethyl alcohol in percent and hydromodule. The best model turns out to be:

$$
z=b_{0}+b_{1} x+b_{2} y
$$

where $x$ is the concentration of ethyl alcohol, $y$ is the hydromodule, and $z$ is the concentration of phenolecarboxylic acids in percent.

After the statistical processing of the data it can be seen that the coefficient of determination $R^{2}=0,81$ which means that $81 \%$ of the change in the parameter $z$ is due to the control factors $x$ and $y$ is described with the model used. Of all the models studied, the coefficient of certainty is the highest. The statistically significant coefficients of the model are as follows:

$$
b_{1}=0,008324, b_{2}=0,011228
$$

Fisher's criterion, $F(3,40)=16.56, p<0.00022$, and its corresponding probability indicate that the model describes a significant part of the change in $z$. The model performs better than the so-called average estimates.

The regression equation is:

$$
y=0,008324 x+0,011228 y
$$

The resulting regression model describes the surface $z=f(x, y)$ that we can depict in $R^{3}$.

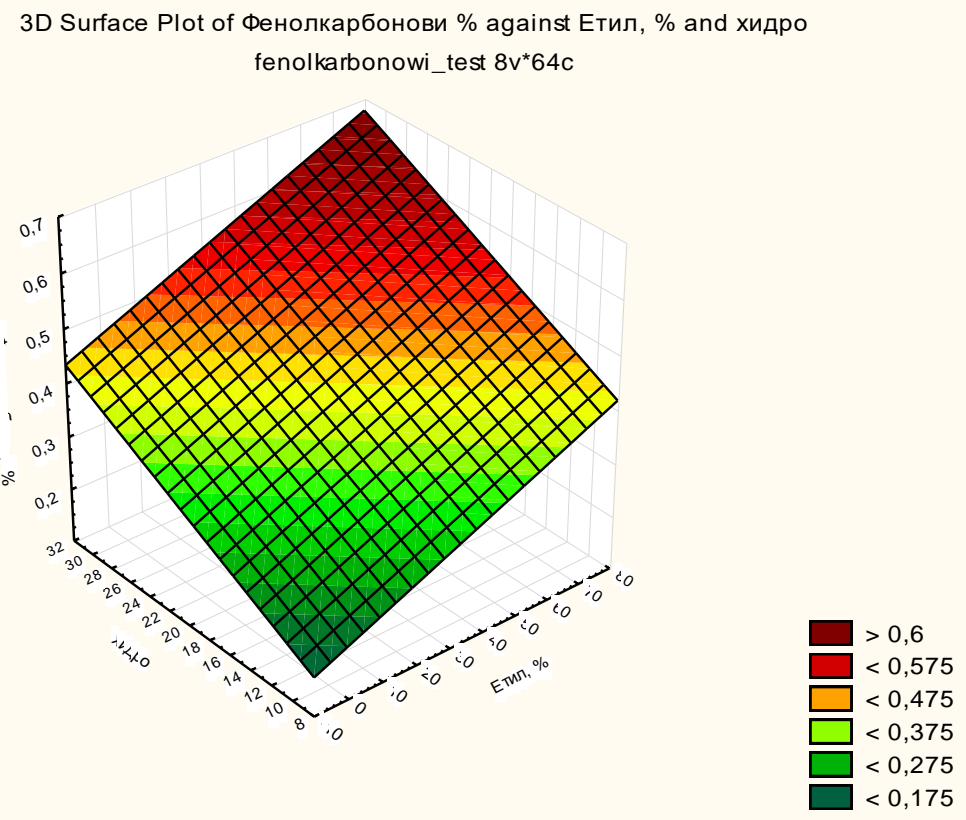

Figure 8. Model response line 


\section{IRTIL $\vee>$}

Ipplied Resseirlohes in Technics, Technologies and Eductition

Journal of the Faculty of Technics and Technologies, Trakia University https://sites.google.com/a/trakia-uni.bg/artte/

The model response line is presented in Figure 8. The analysis of the residuals and their graphical representations are shown in Figure. 9 in the so-called normal probability graph.

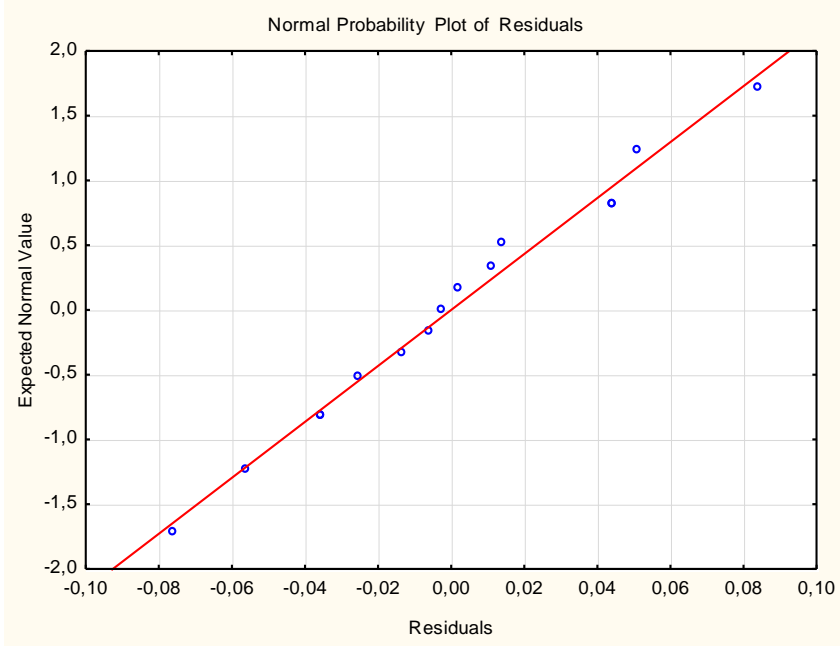

Figure 9. Normal probability plot of residuals

We will check for residual dependence on predicted values from the model. For this purpose, we will analyze the scatterplot of the residuals from the predicted values - Figure 10.

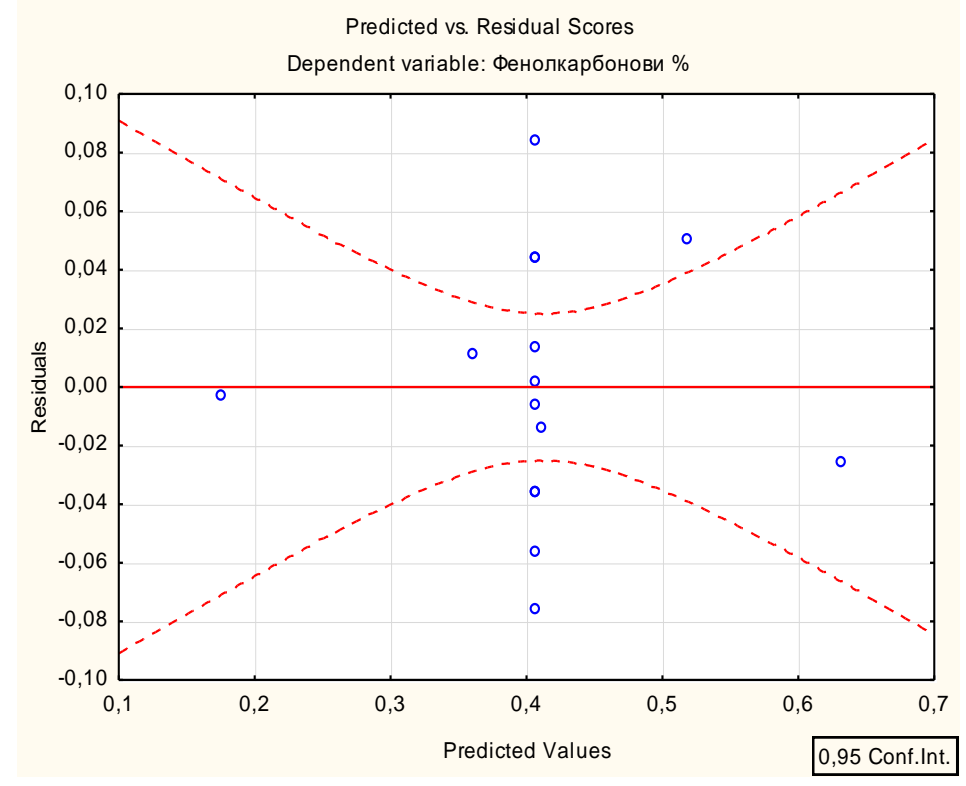

Figure 10. Scatterplot of residual values from predicted values

The obtained graph shows that the residuals are not systematic and are sufficiently chaotic. We can conclude that the residuals do not depend on the predicted values. 
 https://sites.google.com/a/trakia-uni.bg/artte/}

\section{CONCLUSION}

From the obtained results we can draw the following conclusions:

- From the residual analysis, we can conclude that our model is adequate.

- The resulting model is linear and describes with great precision the experimental data obtained.

- Ethyl alcohol concentration has a greater influence on the model of the hydromodule.

\section{REFERENCES}

[1] Rice-Evans C. A., N. J. Miller, and G. Paganga. (1996). Structureantioxidant activity relationships of flavonoids and phenolics acids. Free Radical Biology and Medicine, Vol. 20, No. 7, pp. 933-956.

[2] McDougall G. J., N. N. Kulkarni, and D. Stewart. (2009). Berry polyphenols inhibit pancreatic lipase activity in vitro. Food Chemistry, Vol. 115, No. 1, pp.193-199.

[3] Shukitt-Hale B., R. L. Galli, V. Meterko et al. (2005). Khranitelna dobavka s plodovi polifenoli podobryava vŭzrastoviya defitsit sinbehavioran dneuronalmarkerrisofinflam mationand oxidativestress. Age, Vol. 27, No.1, pp.49-57.

[4] Harborne J. B., Williams C. A. (2000). Advances in flavonoid research since 1992. Phytochemistry, Vol. 55, No. 6, pp. 481-504.

[5] Ames B. N., Shigenaga M. K., Hagen T. M. (1993). Oxidants, antioxidants, and the degenerative diseases of aging. Proc Natl Acad Sci USA. 1993;90(17):7915- 7922.

[6] Ames B. N. (1983). Dietary carcinogens and anticarcinogens. Oxygen radicals and degenerative diseases. Science, Vol. 221, No. 4617, pp. 1256-1264.

[7] Hou D. X. (2003). Potential mechanisms of cancer chemoprevention by anthocyanins. Curr Mol Med, Vol. 3, No. 2, pp. 149-159.

[8] Bagchi D., Sen C. K., Bagchi M., Atalay M. (2004). Antiangiogenic, antioxidant, and anticarcinogenic properties of a novel anthocyanin-rich berry extract formula. Biochemistry (Mosc), Vol. 69, No. 1, pp. 75-80.

[9] Katsube N., Iwashita K., Tsushida T., Yamaki K., Kobori M. (2003). Induction of apoptosis in cancer cells by bilberry (Vaccinium myrtillus) and the anthocyanins. J Agric Food Chem, Vol. 51, No.1, pp. 68-75.

[10] State Pharmacopoeia of Russia. General methods of analysis - II ed., Medicine. 1987. 